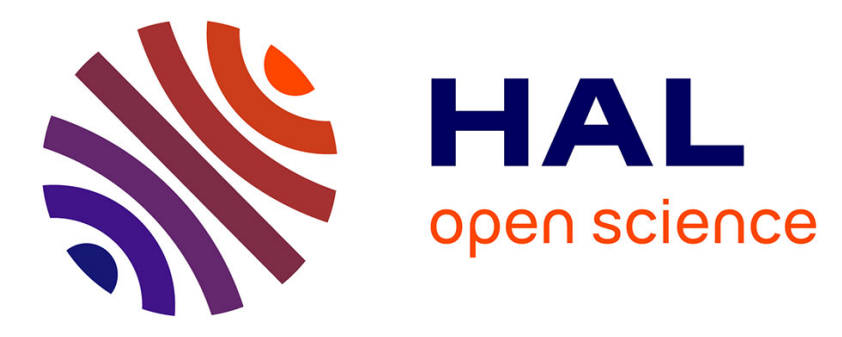

\title{
Predictive Control Framework for HEV: Energy Management and Free-Wheeling Analysis
}

Nicoleta Stroe, Sorin Olaru, Guillaume Colin, Karim Ben-Cherif, Yann

Chamaillard

\section{- To cite this version:}

Nicoleta Stroe, Sorin Olaru, Guillaume Colin, Karim Ben-Cherif, Yann Chamaillard. Predictive Control Framework for HEV: Energy Management and Free-Wheeling Analysis. IEEE Transactions on Intelligent Vehicles, 2019, 4 (2), pp.220-231. 10.1109/TIV.2019.2904416 . hal-02461608

\section{HAL Id: hal-02461608 https://hal.science/hal-02461608}

Submitted on 8 Apr 2020

HAL is a multi-disciplinary open access archive for the deposit and dissemination of scientific research documents, whether they are published or not. The documents may come from teaching and research institutions in France or abroad, or from public or private research centers.
L'archive ouverte pluridisciplinaire HAL, est destinée au dépôt et à la diffusion de documents scientifiques de niveau recherche, publiés ou non, émanant des établissements d'enseignement et de recherche français ou étrangers, des laboratoires publics ou privés. 


\title{
Predictive Control Framework for HEV: Energy Management and Free-Wheeling Analysis
}

\author{
Nicoleta Stroe, Sorin Olaru, Guillaume Colin, Karim Ben-Cherif and Yann Chamaillard
}

\begin{abstract}
The focus of this work is to exploit the potential of model predictive control for the energy management of hybrid electric vehicles. The global framework covers the power distribution between the internal combustion engine and the electric machine(s) in order to minimize the fuel consumption. Current technologies allow the forecast of speed profile and road grade making predictive control a viable solution. The gears within the prediction model are assumed to be pre-calculated at a higher level and therefore, only the torque split problem needs to be addressed by the energy management mechanism. Engine stop can improve fuel gain which is even more noticeable for hybrid vehicles and hence, its inclusion is naturally considered in the present study. Furthermore, optimization of the speed profile is addressed by introducing the free-wheeling functionality.
\end{abstract}

Index Terms-hybrid electric vehicles, predictive control, model-based control

\section{INTRODUCTION}

$\mathbf{H}$ YBRID electric vehicles represent a promising alternative to conventional vehicles in the context of fossil fuel scarcity. A hybrid powertrain contains at least one additional electric machine, that can be used for stop and go, regenerative braking, boost or electric propulsion. One or more of these functionalities can be encountered, depending on the level of hybridization (micro, mild and full hybrid).

Three types of topologies can be identified: parallel, series and series-parallel. In the parallel architecture, both the ICE and EM contribute to traction and their rotational speeds are directly linked to the vehicle speed. Series topologies have two electric machines, one that is used for traction and another that works as a generator. There is no mechanical link between the ICE and the wheels, which presents the advantage of choosing the engine operating point regardless of the vehicle speed. Series-parallel HEV have more complicated transmissions, usually based on planetary gear sets and contain at least two electric machines, between which there is an additional mechanical link via the transmission [1].

The design, modeling and control of hybrid powertrains represent a challenge for both research and industry in different fields. The power distribution between the engine and its electric counterpart, referred to as energy management, is

N. Stroe is with the Powertrain Engineering Department at Renault, Lardy, France and with PRISME Laboratory, Univ. Orleans, France (e-mail: nicoletaalexandra.stroe@univ-orleans.fr)

S. Olaru is with the Laboratory of Signals and Systems, CentraleSupelecCNRS-Univ. Paris-Sud, Univ. Paris-Saclay, Gif-sur-Yvette, France (e-mail: sorin.olaru@centralesupelec.fr)

K. Ben-Cherif was with the Powertrain Engineering Department at Renault, Lardy, France (e-mail: karim-bencherif@mail.nissan.co.jp)

G. Colin and Y. Chamaillard are with PRISME Laboratory, Univ. Orleans, France (e-mail: guillaume.colin@univ-orleans.fr; yann.chamaillard@univorleans.fr) of major interest from a control perspective. The main goal is to minimize fuel consumption, but additional criteria such as pollutant emissions reduction [2] and drivability improvement [3], can also be tackled.

In the literature numerous techniques have been proposed, that will be summarized in the next section. A clear distinction can be made between plug-in hybrid vehicles and those without an external charging. For the former it has been proven that a close-to-global optimum solution is to linearly discharge the battery with respect to distance, for sections with a certain pattern [4]. Hence, the main focus in this case is to exploit long-term telemetry data and to divide the road into segments with similar characteristics. In the absence of external charging, the battery should not be depleted by the end of the drive cycle, because this would imply charging at a later stage, via the engine, which involves additional fuel consumption. For this type of hybrid, it is therefore important to maintain the final state-of-charge between certain limits. In order to correctly evaluate the performance, it is required in simulation that the final value of the state-of-charge must equal the initial one. The goal is twofold: a fair comparison with the consumption of a conventional vehicle and between different control strategies for a given hybrid vehicle. Hence, the energy management in the case without a plug-in requires a different approach, because each consumption in the battery needs to be later compensated, either by regenerative braking, or by the engine.

Current technologies allow the acquisition of future traffic data conditions (from GPS, for instance) that allow the reconstruction of the speed profile and thus, favoring the orientation toward predictive control structures. In the present study, it is assumed that the vehicle speed can be predicted for a horizon up to 1 minute, making it possible to predict the wheel torque demand. Traffic forecast techniques are beyond the scope of this study and therefore, no further information is provided regarding data acquisition and processing.

Model predictive control (MPC) has aroused the interest in the automotive industry, its application spanning several fields, such as engine control [5], lateral vehicle dynamics [6], cruise control [7] or autonomous vehicle [8]. MPC is a constrained optimization strategy, which calculates a sequence of future commands that minimizes a cost function over a prediction horizon, but where only the first command is applied in a receding horizon manner. The simultaneous calculation of a control window, instead of just one command, means that the impact of the value that will be eventually applied to the system can be predicted, reinforcing the recursive feasibility.

In this paper, the gears are considered pre-imposed and the torque distribution between the engine and the electric 
machine is provided by an MPC-based optimization. Engine stop is performed during standstill and regenerative braking, but it can also be shut off during electric propulsion phases. In order to avoid an increase in complexity, the present work deals with engine stop-start based on an a-posteriori modelbased decision, the advantage of such a decision being the reduction of the optimization variable within the MPC problem, as will be detailed in the next sections. As a contribution, freewheeling functionality is introduced, in a predictive control framework. In this case, no pedal is pressed, the driveline is disengaged and thus, the vehicle is slowed down by resistive forces only. The benefit in fuel gain for conventional vehicles was analyzed in [9], [10], but existing MPC techniques do not include this feature to the best of the authors' knowledge. For a hybrid vehicle, an extension is possible, which includes energy recovery. This allows coasting initiation for cases when it would have been too slow in its initial formulation and thus, unacceptable from a performance perspective.

The paper is organized as follows: first, a brief presentation of the existing strategies is given, followed by the powertrain control-oriented model for a specific case-study, but with an extended application to different hybrid architectures. An MPC formulation of the joint problem of torque split and stop-start is next introduced. Finally, an analytical approach of the analysis and problem formulation of a coasting strategy is addressed, this being the main contribution of the present study.

\section{STATE OF THE ART}

Powertrain modeling distinguishes two simulation approaches: forward and backward. The former respects the physical causality of the power flow (from engine to vehicle speed), whereas the latter starts from the target vehicle speed and calculates the references for the propulsion system. A comparison between the two can be found in [11]. The backward approach is used in control-oriented applications, i.e. it is assumed that there is an imposed drive cycle (speed profile) and a control law needs to be designed in order to ensure speed tracking.

As mentioned in the introduction, the energy management unit of an HEV handles the power distribution between the two propulsion elements. If the gears are pre-imposed, either by the drive cycle standards, or calculated at a supervisory level, the problem is reduced to a torque split decision. Therefore, at each step, the wheel torque demand is calculated from the target speed, resistive forces and slope, and a controller then decides the distribution between the ICE and EM. The level where the distribution occurs is defined by the position of the electric machine (crankshaft, gearbox or wheel) and hence, from a control perspective it is useful to propose a model that covers a large class of configurations.

The first attempt toward a generalized model for a $\mathrm{HEV}$ powertrain was made in [12], where an approach based on energy flow was proposed. In [13] a more detailed model was introduced, where an appropriate parametrization allows the representation of different vehicle types: conventional, electric and hybrid. For the latter, the 3 architecture types are handled: series, parallel and series-parallel. Shaft dynamics are included, but the type of transmission and the position of the electric machine for a parallel configuration are not considered.

Over the years, the power distribution problem was handled by different control techniques, whose main goal was to minimize fuel consumption. However, other objectives can also be handled, such as emissions reduction [2], drivability [3] or battery health [14]. Passenger cars are the most targeted category, but over the recent years an increased interest in trucks [15], [16] and buses [17], [18], [19] has been witnessed.

Dynamic programming (DP) [20] provides the global optimum solution, but it assumes that the speed profile is entirely known in advance and it is also very computationally demanding, which makes it generally unsuitable for real-time applications. Therefore, it is only implemented offline and its result used as a reference value. Pontryagin's Minimum Principle (PMP) is sometimes preferred to DP, because it can also yield the optimal solution, but considerably faster, provided the optimal co-state is found, as detailed in [21]. Equivalent Consumption Minimization Strategy (ECMS) is a very popular control approach, derived from PMP and used for online application [22]. It is based on the instantaneous optimization of a cost function expressed as a weighted sum of the two quantities that need to be minimized: the fuel and the electrochemical consumption. The penalty factor is often referred to as the equivalence factor, because each use of the battery has a corresponding fuel consumption. Variations of this method can be encountered, such as Adaptive-ECMS [23] or Telemetric-ECMS [24], that propose different strategies for tuning the penalty factor.

The ability to cope with constraints, but also the current possibility to gather future information about the drive cycle, made MPC an attractive solution, in its deterministic [25], [26] or stochastic form [27], [28]. The use of preview data for improvements in fuel gain has been the object of several papers, such as [29] or [30]. In the former, a maximum headway of $400 \mathrm{~m}$ was tested, whereas in the latter the prediction was specified on a time headway, with optimal values found to be on the order of 30s. However, within the use of the MPC method, smaller prediction horizon values are used, mostly below 20s.

Engine stop-start functionality provides additional fuel gain if handled properly, especially in urban traffic. For a hybrid vehicle it presents an additional interest, due to the possibility of electric propulsion, but it introduces new challenges in the energy management formulation in the MPC framework. In the literature, there are two main approaches to tackle this problem: simultaneous consideration of the torque split and engine stop in the energy management problem, by adding a discrete optimization variable [31] or division into a two-level optimization [32], [33], [19].

Coasting, sometimes also referred to as free-wheeling, is a special functional mode in which the vehicle motion is described only by resistive forces, no pedal being pressed. During coasting, the engine is usually disengaged, in order to avoid the drag torque. In some cases, however, an additional negative torque from the engine can be useful, if a fast decrease of vehicle speed is demanded. If the engine is disconnected from the wheels, it can either be on idle or stopped. 
One of the first papers which tackled the benefit of coasting in terms of fuel consumption for conventional vehicles was [9]. Two types of drive cycle were considered: NEDC (hard deceleration) and FTP-75 (small deceleration). Although the NEDC in its initial form is not representative for coasting, a tolerated speed deviation allows early coasting initiation during phases of constant reference speed. It was shown that a gain up to $6 \%$ can be obtained, whereas for FTP-75, the best-case scenario provides a gain of $10 \%$.

In [10] the performance of coasting was analyzed for constant speed phases on highway, with slope information included. The focus was on conventional vehicles and two main topics were addressed: coasting initiation and influence of boost acceleration before coasting. The performance of an HEV was also tackled for a downhill road profile and results showed that coasting is more fuel-efficient than energy recovery.

\section{A. Abbreviations and acronyms}

- ICE - internal combustion engine

- EM - electric machine

- DCT - dual-clutch transmission

- GB - gearbox

- $\mathrm{R}_{\mathrm{i}}$ - gear ratio engaged on $i^{\text {th }}$ shaft (includes neutral definition), $i \in\{1:$ odd $, 2:$ even $\}$

- $R_{\left.f_{(} R_{i}\right)}$ - axle ratio corresponding to the $R_{i}$ ratio

- $\mathrm{C}_{\mathrm{i}}$ - clutch status (0 - open, 1 - closed)

- $N_{i}=\min \left(R_{i}, 1\right)$ - used to define the case where one of the shafts is decoupled

- $r_{i c e / e m}^{w}$ - ratio between the ICE/EM torque at wheel level and the component (ICE/ EM) torque

- rat $_{\text {em }}$ - ratio between the EM and the corresponding shaft where it is connected

- $\omega_{i c e}^{\text {ctrl }}$ - idle speed or $0 \mathrm{rpm}$, in case of engine stop

- QP - quadratic programming

- S\&S - Stop\&Start

- $A_{f}$ - vehicle frontal area

- $c_{d}$ - aerodynamic drag coefficient

- $c_{r 0}, c_{r 1}$ - rolling friction coefficients

- $\rho_{\text {air }}$ - air density

- $m_{v}$ - vehicle mass

- $R_{w}$ - wheel radius

- $I_{w, d}$ - inertia of one wheel and of driveline, respectively

- $O C V$ - open circuit voltage

- $P_{e}$ - electrochemical power

- $P_{f}$ - fuel power

- $Q_{\max }$ - battery capacity

\section{POWERTRAIN CONTROL-ORIENTED MODEL}

As mentioned in the previous section, the backward approach is suitable for control applications and was therefore chosen in this work. Given the resistive forces and the vehicle reference speed $v$, the wheel torque demand $T_{w}$ can be calculated:

$$
\begin{aligned}
T_{w}=\left(\frac{1}{2} \rho_{a i r} A_{f} c_{d} v^{2}\right. & +\left(c_{r 1} v+c_{r 0}\right) m_{v} g \cos (\alpha) \\
& \left.+m_{v} g \sin (\alpha)+m_{v} \dot{v}\right) R_{w}
\end{aligned}
$$

One of the goals of the control strategy is flexibility with respect to the powertrain architecture. For instance, for a micro-hybrid, characterized by the presence of a belt-driven starter-generator, the torque split problem can be formulated at the crankshaft level, but an electric machine can also be found at the gearbox level (primary or secondary) or at the wheel. Hence, if the control problem is formulated at the wheel level, then a comprehensive description is provided about the transmission type and the electric machine position. If the gear ratios are calculated at a higher level, the only control variables remain the torque of components (ICE and EM).

In this paper, a case-study of a dual-clutch transmission hybrid with an EM connected to the primary shaft as in Fig. 1, was chosen. The static model introduced below describes the relation between the total wheel torque (known at each instant) and the torque of components and it also defines the rotational speeds from the vehicle speed and the gears. In [34] it was shown that the proposed model can be used for all parallel and series hybrid architectures, with a possible extension for seriesparallel, provided additional electric machines on crankshaft and wheel are included. Here, only the relations that concern the current case-study have been retained:

$$
\begin{aligned}
T_{w} & =r_{i c e}^{w} T_{i c e}+r_{e m}^{w} T_{e m} \\
r_{i c e}^{w} & =R_{f_{\left(R_{1}\right)}} R_{1} C_{1}+R_{f_{\left(R_{2}\right)}} R_{2} C_{2} \\
r_{e m}^{w} & =R_{f_{\left(R_{1} C_{1} C_{2}+R_{2}\right)}}\left(R_{1} C_{1} C_{2}+R_{2}\right) r_{a t} \\
\omega_{i c e} & =r_{i c e}^{w} \frac{v}{R_{w}}+\left(1-C_{1}-N_{2} C_{2}\right) \omega_{i c e}^{c t r l} \\
\omega_{e m} & =r_{e m}^{w} \frac{v}{R_{w}}+\operatorname{rat}_{e m} C_{2}\left(1-C_{1}\right)\left(1-N_{2}\right) \omega_{i c e}^{c t r l}
\end{aligned}
$$

For a better understanding of the model, its functional modes are summarized in Table I. The driveline can be open $\left(C_{1}=\right.$ $C_{2}=0$ ) or closed, with one clutch closed at a time. It is possible however to have both clutches simultaneously closed: during take-off and the parallel mode of charge during driving, as depicted in Fig. 2. In this case, the even shaft is on neutral and the EM speed is given by the gear engaged on the odd shaft. Hence, the EM gear is correctly defined by $R_{1} C_{1} C_{2}+R_{2}$; if $R_{2}=0$ and both clutches are closed, then the multiplication ratio is given by $R_{1}$. Another special use-case is charge at standstill, depicted in Fig. 3. Here, the even shaft is decoupled from the wheel $\left(N_{2}=0\right)$, with the even clutch closed $\left(C_{2}=1, C_{1}=0\right)$ and the engine is running at idle speed. The condition that defines when the engine is disconnected from the wheel is therefore given by $C_{1}+N_{2} C_{2}=0$. The EM speed in this case is also calculated from the idle speed $\left(\omega_{i c e}^{\text {ctrl }}\right)$ and the condition that ensures it is $C_{2}\left(1-C_{1}\right)\left(1-N_{2}\right)=1$.

The only dynamical part of the system is the battery stateof-charge, for which an equivalent circuit model is used (OCV 


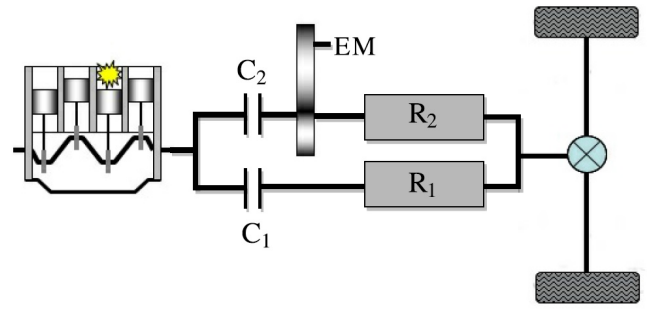

Fig. 1. DCT hybrid configuration

TABLE I

HYBRID DCT FUNCTIONAL MODES

\begin{tabular}{cccc}
\hline$C_{1}$ & $C_{2}$ & $N_{2}$ & Case \\
\hline 0 & 0 & 0 & standstill, sailing \\
\hline 0 & 0 & 1 & electric driving, regenerative braking \\
\hline 0 & 1 & 1 & hybrid or conventional, even gear engaged \\
\hline 0 & 1 & 0 & charge during standstill \\
\hline 1 & 0 & 0 & conventional driving, odd gear engaged \\
\hline 1 & 0 & 1 & hybrid driving \\
\hline 1 & 1 & 0 & take-off, charge during driving (parallel mode) \\
\hline
\end{tabular}

- open circuit voltage, $R$ - internal resistance, $Q_{\max }$ - battery capacity):

$$
S \dot{O} C=-\frac{O C V_{(S O C)}-\sqrt{O C V_{(S O C)}^{2}-4 R_{(S O C)} P_{b}}}{2 R_{(S O C)} Q_{\max }}
$$

where $P_{b}=\frac{\pi}{30} \omega_{e m} T_{e m}+$ loss $\left(\omega_{e m}, T_{e m}\right)$.

\section{A. Fuel consumption approximation}

The engine fuel rate is given as a non linear map with respect to torque and rotational speed. For the control design, an analytical expression with an explicit dependence on the control variable i.e. the engine torque, is needed. The vehicle considered for this case-study is equipped with a turbo-charged 1.2 L SI engine, whose fuel rate dependence on torque is illustrated in Fig. 4, via a parametrization of curves with respect to $\omega_{i c e}$. In this paper, a piecewise linear approximation with respect to torque is introduced, as expressed below:

$$
\dot{m}_{f}=\alpha_{j}\left(\omega_{i c e}\right) T_{i c e}+\beta_{j}\left(\omega_{i c e}\right), \text { for } j=1 \ldots N_{\text {part }}
$$

where $N_{\text {part }}$ is the number of torque partitions.

\section{ENERGY MANAGEMENT - PROBLEM FORMULATION}

As announced in the introduction, the goal is to reduce fuel consumption and the approach is based on MPC. The receding horizon optimization in MPC is based on the definition of a cost function. To evaluate the fuel consumption of a hybrid vehicle, a tank-to-wheel analysis is usually performed. In the case of a hybrid with external charging, the goal is to reach the destination with the battery depleted, i.e. to exploit the potential of the electrical components as much as possible. The battery recharge is not included in the optimization problem, principally due to the fact that such a decision it is not vehicle-related (a comprehensive analysis of the consumption is called well-to-tank and it also considers the production of

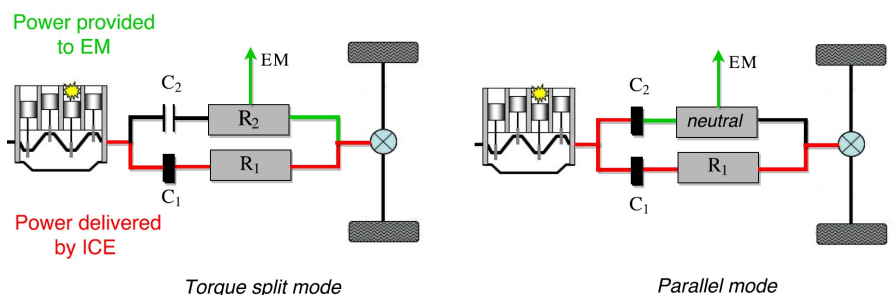

Fig. 2. Charge during driving: torque split and parallel mode

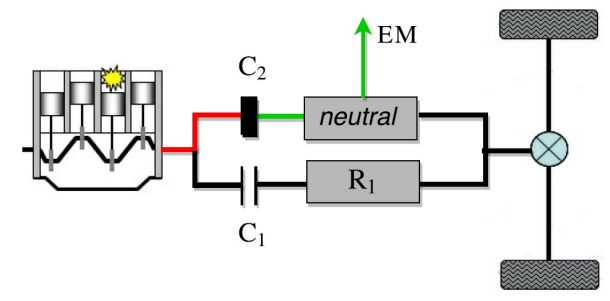

Fig. 3. Charge during standstill

the electricity from the grid). Starting from these considerations the present work focuses on fuel gain optimization for a hybrid configuration without a plug-in and therefore, the battery consumption needs to be explicitly considered. A low battery SOC at the end of the drive cycle implies a reduced fuel consumption, but also a decrease of the energy buffer for a new trip. It is recalled that the gearbox setpoints are handled at a supervisory level and therefore, the energy management addresses only the torque distribution.

The cost function definition is based on PMP (Pontryagin's Minimum Principle) design:

$$
\begin{gathered}
\min _{u_{k}} P_{f_{k}}+\lambda_{k} P_{e_{k}} \\
P_{f_{k}}=H_{L V} \dot{m}_{f_{k}} \text { and } P_{e_{k}}=-Q_{\max } O C V_{k} S \dot{O} C
\end{gathered}
$$

where $k$ is the current step, $H_{L V}$ is the lower heating value of the fuel, $u_{k}$ is the engine torque $T_{i c e}$ and $\lambda_{k}$ is a penalty, also referred to as the equivalence factor.

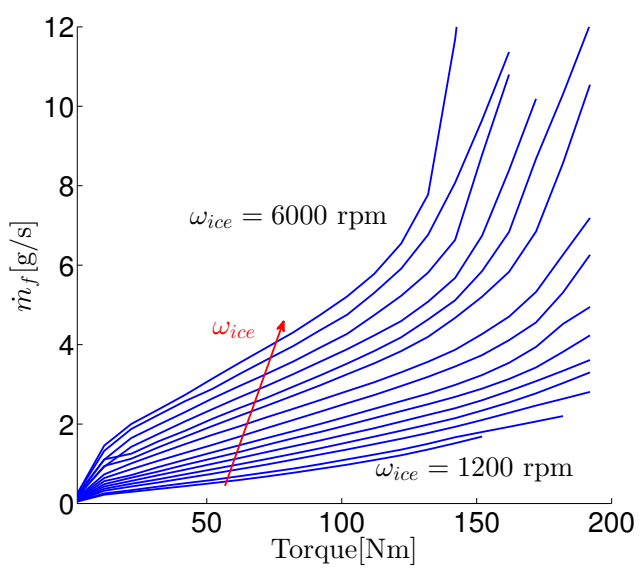

Fig. 4. Fuel rate $\dot{m}_{f}$ evolution with respect to engine torque $T_{i c e}$, for different values of speed $\omega_{\text {ice }}$ 
In this work, a quadratic criterion is defined, where the powers of the two components are introduced with their squared values, but over a prediction horizon, denoted $N_{m p c}$ :

$$
\min _{u} \sum_{i=k}^{k+N_{m p c}-1} P_{f}^{2}(i)+\lambda_{k}^{2}\left(P_{e_{k}}(i)-P_{\text {emin }_{k}}(i)\right)^{2}
$$

The electrochemical power $P_{e}$ can be positive (discharge) or negative (charge), therefore the use of its squared value implies the loss of sign information. The purpose of the displacement term $P_{\text {emin }}$ is to bring the two powers to the same level before adding their squared values.

The penalty factor $\lambda$ has a tremendous impact on the performance and its tuning raises difficulties, as is also the case for PMP. If chosen too low, the battery consumption will not be properly taken into account and thus, a fast depletion will occur. Conversely, if the weighting factor is oversized, the battery may be overcharged. Here, the tuning relies on the ratio of the fuel and electrochemical power variations between their lower and upper limits. Preview information of length $N_{\lambda}\left(N_{\lambda} \geq N_{m p c}\right)$ is exploited for tuning, as depicted in Fig. 5. If the future vehicle speed can be reconstructed over a horizon $N_{\lambda}$, then an average of the aforementioned ratios can be calculated, as expressed below:

$$
\begin{aligned}
& \lambda_{k 0}=\frac{1}{N_{\lambda}-N_{\lambda}^{s t o p}} \sum_{i=1}^{N_{\lambda}}-\frac{P_{f}\left(\bar{u}_{k, i}\right)-P_{f}\left(\underline{u}_{k, i}\right)}{P_{e}\left(\bar{u}_{k, i}\right)-P_{e}\left(\underline{u}_{k, i}\right)} \\
& \lambda_{k}=\lambda_{k 0}+k_{r}\left(S O C_{s p}-S O C_{k}\right) \\
& N_{\lambda}^{\text {stop }} \text { - no. of predicted steps of vehicle standstill } \\
& \bar{u}_{k, i}\left(\underline{u}_{k, i}\right) \text { - maximum (minimum) of } u_{k, i} \\
& S O C_{s p} \text { - SOC setpoint }
\end{aligned}
$$

It can be noticed that there is a proportional feedback term in the SOC (in this case, $S O C_{s p}$ is constant and equal to the initial SOC). The purpose is to adjust the penalty with respect to SOC variation: if the trajectory is below the setpoint, $\lambda_{k}$ will increase and a stronger penalty implies a reduced use of the battery. If SOC is greater than the setpoint, then $\lambda_{k}$ will decrease, which will favor electrical traction. The proportional factor $k_{r}$ is chosen such that $\lambda_{k}$ remains positive. For a given powertrain, an interval for the feed-forward component variation can be determined, regardless of the drive cycle. Therefore $k_{r}$ tuning is made for the worst-case scenario, i.e. the lowest value of $\lambda_{k 0}$ and $S O C_{k}=S O C_{\max }$.

\section{A. MPC formulation}

MPC is a model-based method that calculates at each instant a sequence of commands that minimize a cost function over a finite horizon, under constraints, but only the first command is applied. There are therefore three aspects that need to be defined: a control-oriented model, an optimization criterion and constraints. As far as the former is concerned, linear models are mostly preferred, whereas for the cost function, a quadratic formulation is traditionally chosen. MPC is especially suitable for tracking problems where the anticipation of the system evolution subject to future commands improves the control performance. MPC minimizes the tracking error and

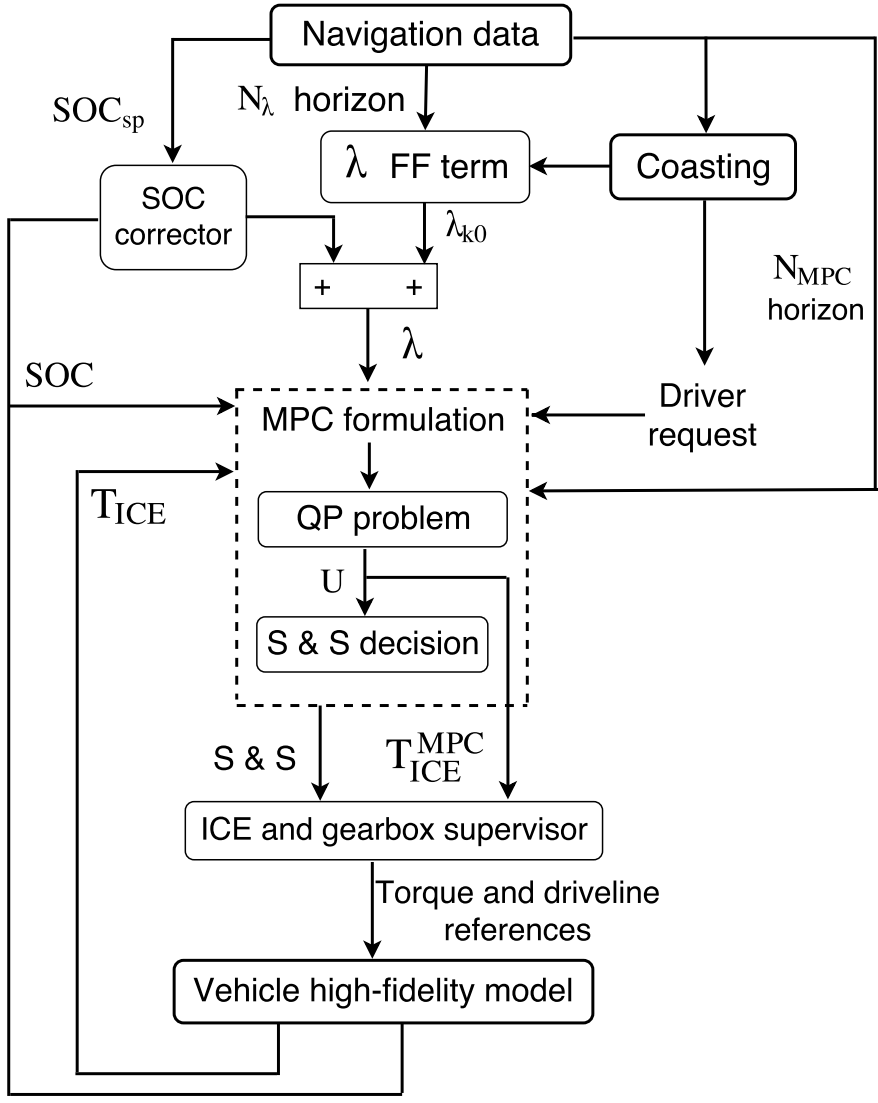

Fig. 5. Generic predictive control strategy. The uppermost level exploits the navigation data for the calculation of the SOC setpoint $S O C_{s p}$ (however, in the present study, this value was kept constant and equal to initial SOC) and of the feedforward component of the penalty factor $\lambda$ and it also interferes in the coasting strategy. The next level concerns the MPC-based torque distribution, which provides the engine torque setpoint and S\&S command. These signals are processed by an engine and gearbox supervisor, which eventually sends the torques, clutches and gearbox number references to a vehicle high-fidelity model.

the command effort, under state and command constraints. In the absence of a setpoint tracking, MPC optimizes an energy criterion in which case it is referred to as Economic MPC (EMPC) [35].

The current problem can also be included in the framework of EMPC. The goal is to minimize a criterion that reflects an energy consumption (thermal and electrochemical), subject to constraints, but no tracking problem is addressed. If SOC tries to reach a steady-state value, the potential of the energy buffer (the battery) is not exploited. Therefore, SOC is allowed to freely evolve between the physical limits of the components.

The prediction model is based on the dynamics of the state of charge. Despite the scalar state, the nonlinearity is important and it will be represented for prediction purposes by a linear time-varying (LTV) model.

$$
x_{k+1}=x_{k}+B_{k} u_{k}+D_{k}
$$

where $x(k)=S O C(k), u_{k}=T_{I C E}(k), D_{k}$ is a residual term resulting from linearization. It can be seen that the model represents practically an integrator-like dynamics, with $B_{k}$ and $D_{k}$ time-varying, dependent on wheel torque demand $T_{w}(k)$ and EM rotational speed $\omega_{E M}(k)$. It is assumed that the 
open circuit voltage $(O C V)$ and the internal resistance $(R)$ of the battery remain constant during the prediction. Therefore, the problem can be formulated in the quadratic programming framework, for which efficient solvers exist:

$$
\begin{gathered}
\min _{U} \frac{1}{2} U^{T} H U+F^{T} U \\
\text { s.t. }\left\{\begin{array}{l}
A_{\text {ineq }} U \leq b_{\text {ineq }} \\
A_{\text {eq }} U=b_{\text {eq }}
\end{array}\right.
\end{gathered}
$$

With the definitions from (8) and (10), the matrices involved in the QP formulation can be expressed as:

$$
\begin{aligned}
& H_{k}=\bar{\alpha}_{k}^{2}+q_{k}^{2} \bar{B}_{k}^{2} \\
& F_{k}=\bar{\alpha}_{k} \bar{\beta}_{k}-q_{k}^{2} \bar{B}_{k} U_{k}^{\max }
\end{aligned}
$$

where $q_{k}=\lambda_{k} \frac{1}{H_{L V}} Q_{\max } O C V_{k}, \quad \bar{B}_{k}=\operatorname{diag}\left(B_{k+i-1}\right)$,

$$
\begin{aligned}
& \overline{\alpha_{k}}=\left[\begin{array}{ccc}
\alpha_{j_{1}}\left(\omega_{i c e_{k}}\right) & \cdots & 0 \\
\vdots & \ddots & \vdots \\
0 & \cdots & \alpha_{j_{N_{m p c}-1}}\left(\omega_{i c e_{k+N_{m p c}-1}}\right)
\end{array}\right] \text {, } \\
& \bar{\beta}_{k}=\left[\begin{array}{lll}
\beta_{j_{1}}\left(\omega_{i c e_{k}}\right) & \cdots & \beta_{j_{N_{m p c}-1}}\left(\omega_{i c e_{k+N_{m p c}-1}}\right)
\end{array}\right],
\end{aligned}
$$

where the index $j_{i}$ denotes the fuel consumption region $j$ for the $i$ th element, with $\alpha$ and $\beta$ taken from (8); $U_{k}^{\max }$ is a vector with the control upper bounds.

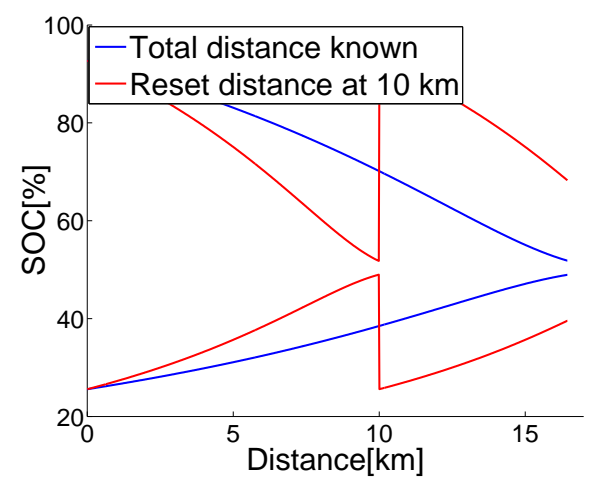

Fig. 6. SOC limits for 2 cases: total distance known and reset distance fixed at $10 \mathrm{~km}$, respectively

The constraints are defined with respect to physical limitations of torque and power, but the SOC balance problem needs to be handled separately. For a hybrid without external charging, it is usually required to have at the end of the drive cycle the same SOC value as in the beginning. In this way, a fair comparison with a conventional vehicle or between different strategies can be made. The solution proposed here is the use of distance-varying limits:

$$
\begin{aligned}
& S O C_{k}^{\text {min }}=S O C_{0}-\left(S O C_{0}-S O C_{\text {min }}\right) e^{1-\frac{1}{1-\frac{d_{k}}{d_{T o t}}}} \\
& S O C_{k}^{\text {max }}=S O C_{0}+\left(S O C_{\max }-S O C_{0}\right) e^{1-\frac{1}{1-\frac{d_{k}}{d_{T o t}}}}
\end{aligned}
$$

where $S O C_{\min }, S O C_{\max }$ are the physical lower and upper bounds (usually with values of $20 \%$ and $90 \%$, respectively), $d_{k}$ is the current distance and $d_{T o t}$ is the drive cycle total distance.
The purpose is to force the SOC trajectory to approach the initial value, as the vehicle reaches its destination. This condition implies knowledge of the total distance, which is not always realistic, without an explicit declaration from the driver, as can be the case when the energy management is in direct relationship with the navigation unit. An alternative is the use of a reset distance, as depicted in Fig. 6. In simulation, this can be set to standard drive cycles distances, but in practice it can be extracted from the driver's history data.

The constraints are hence expressed as below:

$$
\begin{aligned}
& T_{i c e}^{\min }\left(\omega_{i c e}\right) \leq T_{i c e} \leq T_{i c e}^{\max }\left(\omega_{i c e}\right) \\
& T_{e m}^{\min }\left(\omega_{e m}\right) \leq T_{e m} \leq T_{e m}^{\max }\left(\omega_{e m}\right) \\
& S O C_{k}^{\text {min }}-\epsilon_{k} \leq X_{k} \leq S O C_{k}^{\max }+\epsilon_{k}
\end{aligned}
$$

where $\epsilon_{k}$ is a slack variable used to soften the constraints, in order to avoid infeasibility problems that may occur when the SOC variation range is too narrow.

\section{B. ICE stop-start strategy}

It is assumed that the driveline states (gears and clutches) are calculated at the supervisory level and used as inputs by the MPC controller. The ICE can be stopped during standstill and regenerative braking, but also during pure electric traction. The inclusion of stop-start functionality makes the optimization more complex due to the discrete nature of the problem. In order to avoid the introduction of an additional optimization variable, an a-posteriori stop decision based on the sequence of calculated future commands is introduced here.

Let $t_{i d l e}$ be the number of seconds of idling that corresponds to the cost of a restart, $\Delta t_{\text {opt }}$ the MPC sampling time and $c t_{o n}$ the number of steps after an ICE restart. Then, the condition to stop the engine is given by:

$$
\begin{aligned}
& U_{k}\left(1: N_{\text {stop }}\right) \leq T_{i c e}^{\text {thr }} \\
& c t_{\text {on }}>N_{\text {start }}
\end{aligned}
$$

where $N_{\text {stop }}=\frac{t_{i d l e}}{\Delta t_{\text {opt }}}$ and $T_{i c e}^{t h r}$ is an ICE torque threshold below which it is preferable to stop the engine. The condition (17b) is introduced in order to avoid frequent stops; here, the choice $N_{\text {start }}=N_{\text {stop }}$ was made. With this approach, the cost of a restart is implicitly included in the length of the considered subsequence of commands.

The access to a sequence of future commands allows the tuning of $N_{\text {on }}$, representing the restart prediction step in order to improve speed tracking. If the value of the command on the position $1+N_{\text {on }}$ exceeds the ICE torque threshold, then a restart command is activated. For the current study, a sampling time of $0.5 \mathrm{~s}$ was used and thus, $N_{\text {on }}$ was set to 1 . The strategy is detailed in Fig. 7.

\section{Simulations and results for MPC with $S \& S$ functionality}

The strategy was validated in Matlab/Simulink, in cosimulation with AMEsim, used for the high-fidelity modeling of the vehicle. The MPC sampling time was set to $\Delta t_{\text {opt }}=$ $0.5 \mathrm{~s}$, the cost of a restart $t_{i d l e}=2 \mathrm{~s}$ and hence, $N_{\text {stop }}=4$, $T_{i c e}^{t h r}=5 \mathrm{Nm}$. An MPC horizon of $5 \mathrm{~s}$ was chosen, which is long enough to include the $\mathrm{S} \& S$ functionality. Simulations 


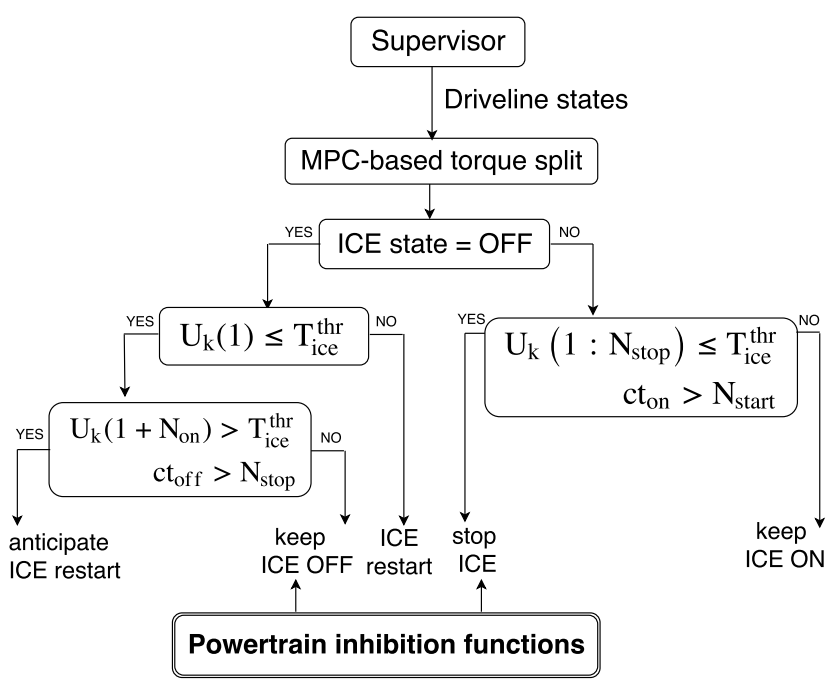

Fig. 7. Schematic representation of S\&S strategy
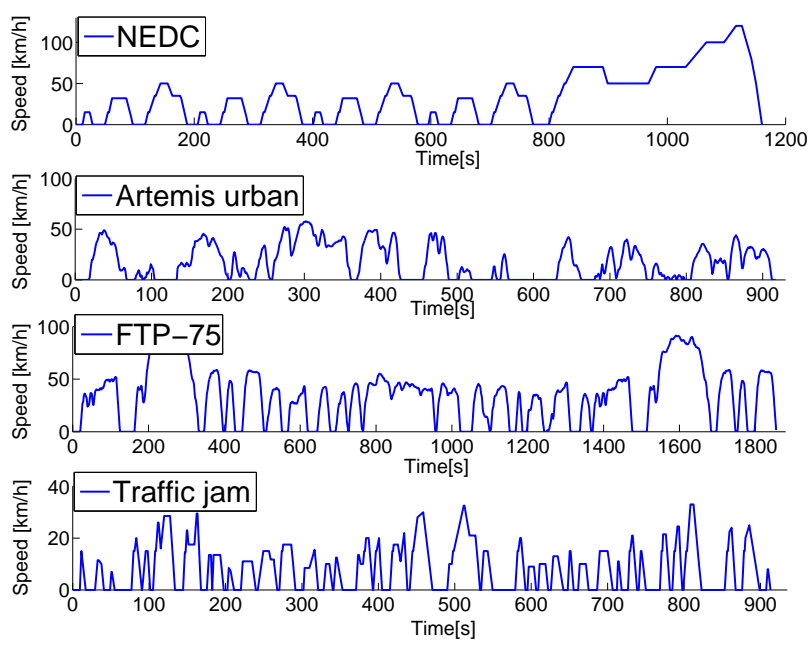

Fig. 8. Speed profile for different representative drive cycles

were carried out for different drive cycles, depicted in Fig. 8. The preview horizon $N_{\lambda}$ for the tuning block can vary between $5 \mathrm{~s}$ and $60 \mathrm{~s}$ and its choice depends mostly on the availability of navigation data and on drive cycle characteristics. A sensitivity analysis with respect to tuning horizon $N_{\lambda}$, as well as a robustness study can be found in [36]. Here, the value that provides the best results was retained for each scenario. Consumption results are summarized in Table II, where a comparison with the performance of the PMP method is made, given by relation (9). In [37] it is shown that this Hamiltonian based method, with a constant, drive cycle dependent adjoint state, gives close to global optimum results. Therefore, for each drive cycle, a constant equivalence factor was determined offline such that the final SOC is the same as for the trajectory obtained with MPC. The engine stop was performed for the phases of electric traction. It can be noticed that a control horizon of $5 \mathrm{~s}$ is enough to obtain a performance down to $6 \%$ close to PMP solution.
TABLE II

FUEL CONSUMPTION [L/100KM] AND FINAL SOC[\%], PMP AND MPC

\begin{tabular}{|c|c|c|c|}
\hline Cycle Strategy & PMP & MPC & $\begin{array}{c}\text { Relative } \\
\text { difference }\end{array}$ \\
\hline NEDC & $\begin{array}{c}4.5 \\
(70.26 \%)\end{array}$ & $\begin{array}{c}4.76 \\
(70.57 \%)\end{array}$ & $5.77 \%$ \\
\hline Artemis urban & $\begin{array}{c}5.61 \\
(52.76 \%)\end{array}$ & $\begin{array}{c}6.11 \\
(52.58 \%)\end{array}$ & $8.9 \%$ \\
\hline FTP-75 & $\begin{array}{c}4.5 \\
(55.74 \%)\end{array}$ & $\begin{array}{c}4.82 \\
(55.16 \%)\end{array}$ & $7.11 \%$ \\
\hline Traffic jam & $\begin{array}{c}5.55 \\
(50.12 \%)\end{array}$ & $\begin{array}{c}6.16 \\
(50.32 \%)\end{array}$ & $11 \%$ \\
\hline
\end{tabular}
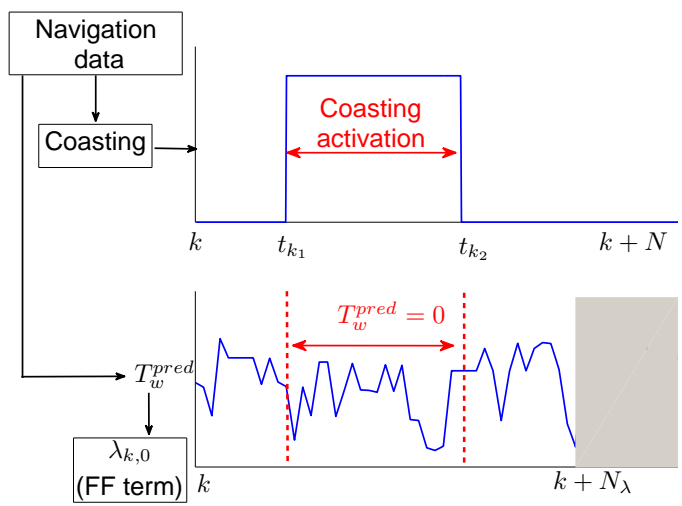

Fig. 9. Coasting initiation: details about influence on the wheel torque prediction and, hence $\lambda$ feed-forward component

\section{COASTING}

As a supplementary feature with respect to the predictive energy management, the goal in this study was to introduce a coasting functionality and to analyze its performance for an HEV. First, a framework for the scenarios where coasting is potentially preferable over regeneration needed to be defined. Second, a strategy that determines coasting acceptance in terms of speed deviation and position, as well as the satisfaction of time-dependent constraints was designed. A method to determine coasting initiation and duration is also detailed.

\section{A. Motivation: basic case-study}

In order to motivate the coasting, a basic case-study is considered, described by a constant speed, followed by a decrease and shortly afterwards, a new increase phase, as depicted in Fig. 10 (black, dashed curve). Two scenarios are handled: basic coasting (red) and $e$-coasting (blue). The latter is defined by free-wheeling with energy recovery and it can be preferred in some cases, if the vehicle cannot be slowed down fast enough by coasting, as will be presented in the next example. If coasting is initiated around $t=82 \mathrm{~s}$, after $21 \mathrm{~s}$ the vehicle will reach the new reference speed from the acceleration section, without deviating significantly from the setpoint. E-coasting can be started later and as a result of the energy recovery, the speed decreases faster and thus, remains closer to the setpoint.

The coasting decision is taken at the supervisory level, as depicted in Fig. 5, from the exploitation of the navigation data. This will influence the current driver request (coasting 
activation implies no pedal pressed), as well as the wheel torque prediction, that will affect the value of the feedforward component of the MPC tuning factor $\left(\lambda_{k 0}\right)$, as shown in Fig. 9. The purpose of this subsection is to evaluate the benefit of coasting from a fuel consumption perspective. For the following analysis, the coasting decision was taken offline and the problem formulation (start and end of coasting) will be introduced in the next subsection.

Simulations were carried out for the three scenarios: baseline, coasting and e-coasting for $N_{M P C}=5 \mathrm{~s}$ and $N_{\lambda}=10 \mathrm{~s}$. Consumption results show that coasting brings an improvement of almost 3\%: $4.98 \mathrm{~L} / 100 \mathrm{~km}$ vs $5.15 \mathrm{~L} / 100 \mathrm{~km}$, as it is obtained with the baseline strategy, for almost the same distance, whereas the improvement with e-coasting is poorer, as shown in Table III. The evolutions of engine speed, engine torque and battery SOC are depicted in Fig. 11. The red trajectory of SOC remains constant in the interval $[82 ; 103] \mathrm{s}$, whereas the curve in black shows a slight decrease before increasing due to regenerative braking, followed by a new decrease in the acceleration part. The early initiation of coasting (during the constant speed phase) allows the engine to be stopped earlier. Moreover, due to coasting, the engine is kept shut off longer, even during the beginning of acceleration, thus improving fuel gain. It can be noticed that the engine torque before coasting initiation is different in the three cases. This is due to variations in the feed-forward component $\lambda_{k 0}$ calculation: the predicted wheel torque is different, zero during coasting and constant negative during e-coasting. The engine torque continues to have a different evolution, even after coasting deactivation (when $\lambda_{k 0}$ is the same) for the following reasons: the SOC trajectory changes, too, and therefore the feedback component is different, and the prediction model is linearized at a distinct operating point (current engine torque and SOC). The e-coasting speed trajectory is very close to the reference speed and hence, the performance is similar too, with the major difference that the engine can be stopped earlier.

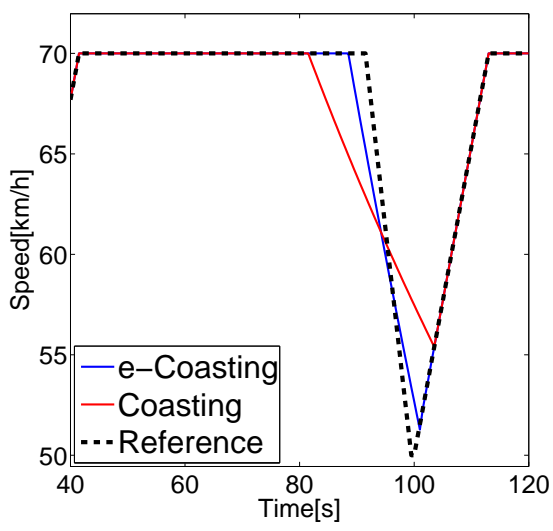

Fig. 10. Speed profile of a basic case-study with flat road. Comparison between coasting with recovery (blue) and baseline coasting (red)

This elementary case-study shows that instead of decelerating only to accelerate after a short time, it is more fuelfriendly to leave the vehicle in free-wheeling mode. Coasting avoids degrading battery efficiency, as a result of bidirectional
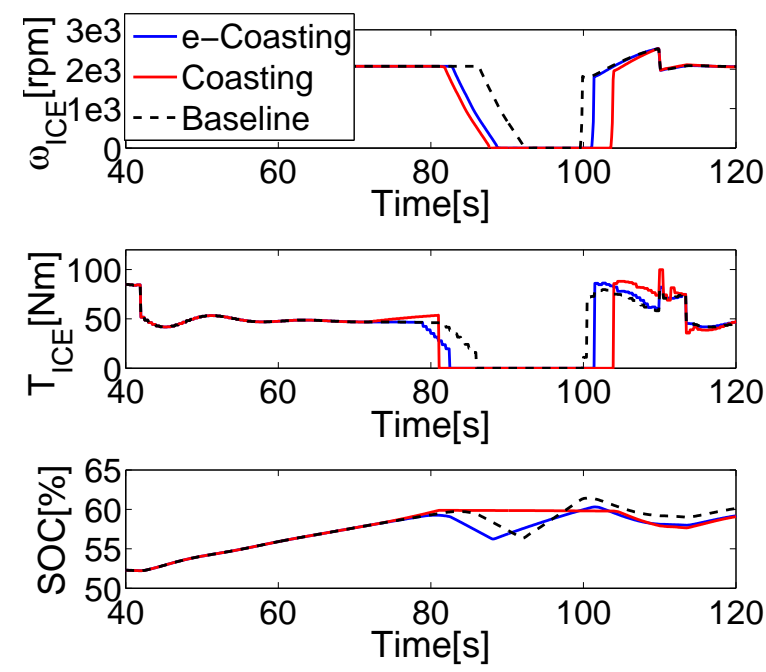

Fig. 11. Simulation results for a basic case-study with flat road: coasting with recovery (e-Coasting), coasting and baseline

TABLE III

PERFORMANCE OF THE CONSIDERED SCENARIOS, SPEED FROM FIG. 10

\begin{tabular}{|c|c|c|c|}
\hline Scenario & e-Coasting & Coasting & Baseline \\
\hline $\begin{array}{c}\text { Performance } \\
\text { (final SOC) }\end{array}$ & $\begin{array}{c}5.07 \\
(52 \%)\end{array}$ & $\begin{array}{c}4.98 \\
(52.05 \%)\end{array}$ & $\begin{array}{c}5.15 \\
(51.9 \%)\end{array}$ \\
\hline Distance[km] & 2.51 & 2.505 & 2.517 \\
\hline RMS error speed $[\mathrm{km} / \mathrm{h}]$ & 0.72 & 1.66 & 0 \\
\hline
\end{tabular}

power exchanges (charge, followed by a discharge) and allows the engine to be stopped for a longer time, not only during deceleration, but also at the beginning of the acceleration phase. The feasibility of coasting depends on the possibility of vehicle self-deceleration: if the resistive forces are not strong enough, the free-wheeling may be too slow with respect to the real speed. The acceptance of the solution may be defined by limits on speed deviation, constraints on position (obstacles, stop points) and preservation of the total distance.

In Fig. 12 a basic case-study with a lower speed is introduced, for which coasting may be unacceptable, in the presence of a deviation from $35 \mathrm{~km} / \mathrm{h}$ to $45 \mathrm{~km} / \mathrm{h}$. In Fig. 13 simulation results are depicted and Table IV summarizes the performances. The same observations can be made about the torque and the SOC evolutions as for the previous casestudy. However, there is no longer an engine stop anticipation for the coasting and the electrical traction is initiated during the constant speed phase for the baseline strategy. The final SOC is not the same for the three strategies and hence, a fair comparison between them is not possible, but it can be seen that e-coasting, with a slightly different speed trajectory, has the potential of improving fuel gain.

\section{B. Problem formulation and proposed solution}

In [10] an analytical approach was introduced for coasting initiation, by writing the energy balance i.e. work and kinetic and potential energy variation. The resistive forces expression 


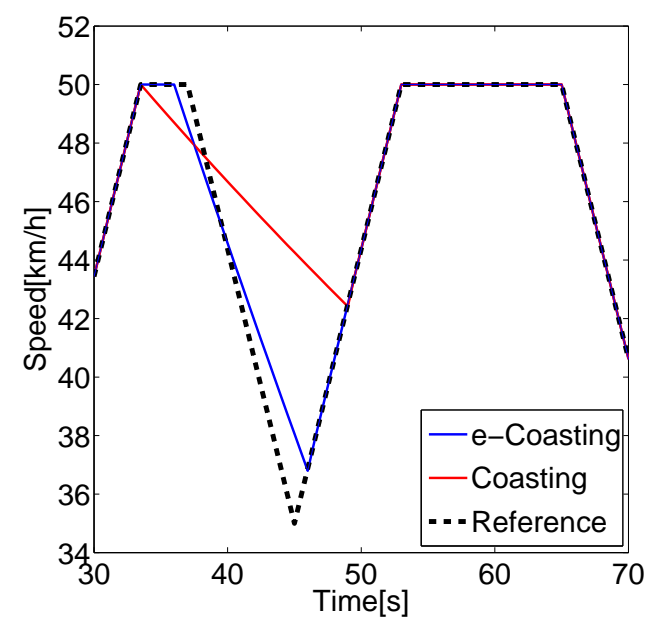

Fig. 12. Speed profile of a basic low-speed case-study with flat road. Comparison between coasting with recovery (blue) and baseline coasting (red)
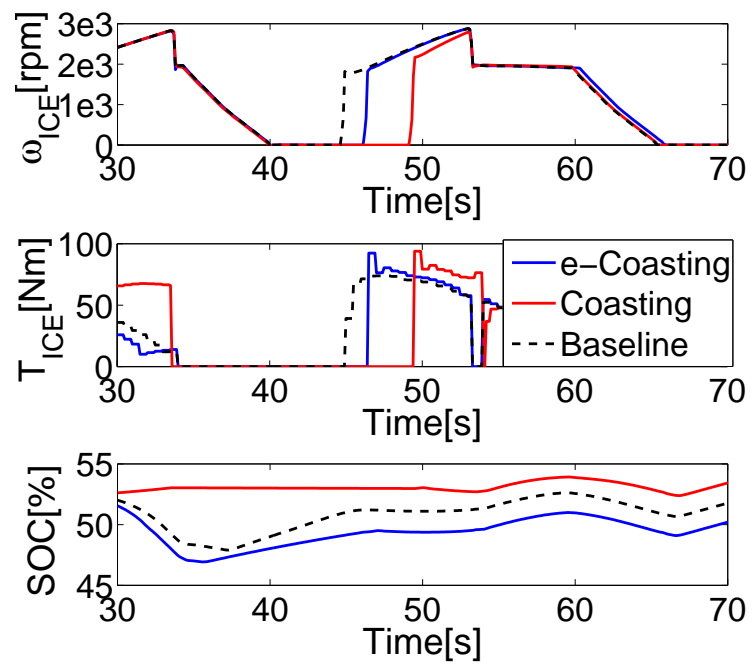

Fig. 13. Simulation results for a basic low-speed case-study with flat road: coasting with recovery (e-Coasting), coasting and baseline

however does not contain the viscous loss, only the dry friction and aerodynamic drag. Moreover, only the constant speed scenario is considered and therefore it is enough to evaluate the speed deviation at the end of coasting in order to decide on the acceptability of the operation. In a general framework, with a variable reference speed as presented in the previous section, the speed evolution during coasting needs to be explicitly considered at each time step or position. In [38], analytical expressions for speed and distance as functions of time were provided and were used in the present study. Following the notations from the aforementioned paper, freewheeling equation can be expressed as:

$$
-\frac{\delta}{g} \frac{d v}{d t}=a+b v+c v^{2}
$$

where $\delta=1+\frac{n I_{w}+I_{d}}{m_{v} * R_{w}^{2}}$ ( $n$ - number of wheels) and $a, b, c$ represent the coefficients of the resistive forces from (1),
TABLE IV

PERFORMANCE OF THE CONSIDERED SCENARIOS, SPEED FROM FIG. 12

\begin{tabular}{|c|c|c|c|}
\hline Scenario & e-Coasting & Coasting & Baseline \\
\hline $\begin{array}{c}\text { Performance } \\
\text { Consumption [L/100km] } \\
\text { (final SOC) }\end{array}$ & $\begin{array}{c}5.46 \\
(51.3 \%)\end{array}$ & $\begin{array}{c}5.52 \\
(54.52 \%)\end{array}$ & $\begin{array}{c}5.76 \\
(52.87 \%)\end{array}$ \\
\hline Distance[km] & 0.69 & 0.7 & 0.695 \\
\hline RMS error speed [km/h] & 0.55 & 2.05 & 0 \\
\hline
\end{tabular}

divided by the vehicle weight $m_{v} g$. The following calculations are valid under the assumption that these coefficients are constant, which implies a road with a piecewise-constant slope.

If expression (18) is inverted, then: $-\frac{g}{\delta}=\frac{1}{a+b v+c v^{2}} d v$. The coasting time can therefore be directly extracted:

$$
-\frac{g c}{\delta} T=\int \frac{1}{\frac{a}{c}+\frac{b}{c} v+v^{2}} d v
$$

Let:

$$
\begin{gathered}
B=\frac{g}{2 \delta} \sqrt{4 a c-b^{2}}, \quad h=\frac{g b}{2 \delta} \\
\beta=\operatorname{atan}\left(\frac{1}{B}\left(\frac{g}{\delta} c v+h\right)\right)
\end{gathered}
$$

Then, the coasting time between speed $v_{1}$ and $v_{2}$ is $T_{\text {coast }}=$ $\frac{\beta_{1}-\beta_{2}}{B}$.

The nominator can be expressed as: $\frac{a}{c}+\frac{b}{c} v+v^{2}=$ $\left(v+\frac{b}{2 c}\right)^{2}+\left(\frac{\sqrt{4 a c-b^{2}}}{2 c}\right)^{2}$. Let $T=T_{\text {coast }}-t$. Then, the speed evolution in time, in the new coordinates, is:

$$
V(T)=\frac{\delta}{g c}\left[B \tan \left(B T+\beta_{2}\right)-h\right]
$$

The evolution in time of the position can be determined by integrating the speed expression. By using $\int \tan x d x=$ $-\ln (\cos x)$, we have:

$$
D(T)=\frac{\delta}{g c}\left(\ln \frac{\cos \beta_{2}}{\cos \left(B T+\beta_{2}\right)}-h T\right)
$$

In this work the decision to initiate coasting is taken after the evaluation of a cost function that includes the speed deviations in time, maximizes the coasting time $T_{\text {coast }}$ and ensures that at the end of coasting, the vehicle speed is close to reference speed (thus avoiding strong compensations from the driver model, that will result in additional fuel consumption). Two approaches are proposed. Let $t_{k_{1}}, t_{k_{2}}$ denote the moment of coasting start and stop, respectively and therefore, $t_{k_{2}}=t_{k_{1}}+\frac{T_{\text {coast }}}{\Delta t_{\text {opt }}} ; v_{\text {ref }}$ the reference speed and $\Delta v\left(t_{k}\right)=v\left(t_{k}\right)-v_{\text {ref }}\left(t_{k}\right)$.

The first cost function has the following expression:

$$
\begin{array}{r}
J_{1}\left(t_{k_{1}}, t_{k_{2}}\right)=\frac{1}{N_{t}} \sum_{t_{k}=t_{k_{1}}}^{t_{k}=t_{k_{2}}-1} \Delta v\left(t_{k}\right)^{2}+ \\
+\beta v\left(t_{k_{2}}\right)^{2} \\
+\beta \frac{1}{T_{\text {coast }}^{2}}
\end{array}
$$

where $N_{t}=t_{k_{2}}-t_{k_{1}}-1$.

The second cost function considers the cumulative speed error during coasting, relative to the reference speed, but not for the final speed deviation. The purpose is to assign high 
penalties to variations at lower speeds (a deviation from 90 $\mathrm{km} / \mathrm{h}$ to $80 \mathrm{~km} / \mathrm{h}$ is acceptable, whereas from $50 \mathrm{~km} / \mathrm{h}$ to 40 $\mathrm{km} / \mathrm{h}$ may not be possible), but at the end of coasting, it is necessary to have a speed as close as possible to the reference, regardless of its order of magnitude.

$$
\begin{aligned}
J_{2}\left(t_{k_{1}}, t_{k_{2}}\right)= & \frac{1}{N_{t}} \sum_{t_{k}=t_{k_{1}}}^{t_{k}=t_{k_{2}}-1} \Delta v\left(t_{k}\right) \frac{\Delta v\left(t_{k}\right)}{v_{\text {ref }}\left(t_{k}\right)} \\
& +\alpha\left|\Delta v\left(t_{k_{2}}\right)\right|+\beta \frac{1}{T_{\text {coast }}}
\end{aligned}
$$

The differences between the results given by the two cost functions are depicted in Fig.15 and 16. It can be seen that the second cost function avoids coasting initiations at low speeds (Fig. 15, upper left corner) as a result of using the relative error.

Cost function evaluation: Coasting initiation relies on three aspects:

- start of coasting $\left(t_{k_{1}}\right)$

- end of coasting $\left(t_{k_{2}}\right)$

- validation of the solution acceptance (value of $J_{1(2)}$ )

Coasting is therefore not included in MPC-based energy management, but is handled at the supervisory level, as in Fig. 5. This choice is dictated by several reasons:

- the two problems do not operate with the same prediction horizons $\left(N_{\text {coast }}>N_{m p c}\right)$ and therefore, a time-scale separation needs to be performed

- coasting activation implies a modified driver behavior, which is situated by design at a supervisory level, the MPC structure receiving as input the actual wheel torque demand and the foreseen values

- under the assumption that the predictive control problem had not the aforementioned hierarchical structure (i.e. simultaneous optimization of the torque split and of the vehicle speed), the problem would be formulated in a hands-off control framework [39]. This implies however the use of a non differentiable cost and hence, a bi-level optimization is preferred.

Given a road preview of length $N_{\text {coast }}$, the first step is the detection of potential coasting initiation. As shown in the previous subsection, the target scenarios are described by a deceleration, followed immediately by an acceleration. Hence, a check is performed on the acceleration sign change in 2 consecutive steps, from negative to strictly positive. Coasting should therefore be initiated at the latest at the start of deceleration $\left(t_{k_{1}}^{\max }\right)$. An early start is also possible, for constant speed phases or with only minor variations. Therefore, $t_{k_{1}} \in\left[t_{k_{1}}^{\min }, t_{k_{1}}^{\max }\right]$, where the lower bound is several steps ahead the upper limit. The next aspect is the end of coasting, which has a lower bound given by the duration of deceleration. Strong accelerations and decelerations are $a$ priori penalized.

The cost function $J_{1}$ or $J_{2}$ is evaluated by varying $t_{k_{1}}$ and $t_{k_{2}}$ between their lower and upper bounds. The values of $t_{k_{1}}$ and $t_{k_{2}}$ that correspond to the minimum are retained, provided the solution is acceptable, by comparing the minimal value with a pre-defined threshold (in order to avoid large speed

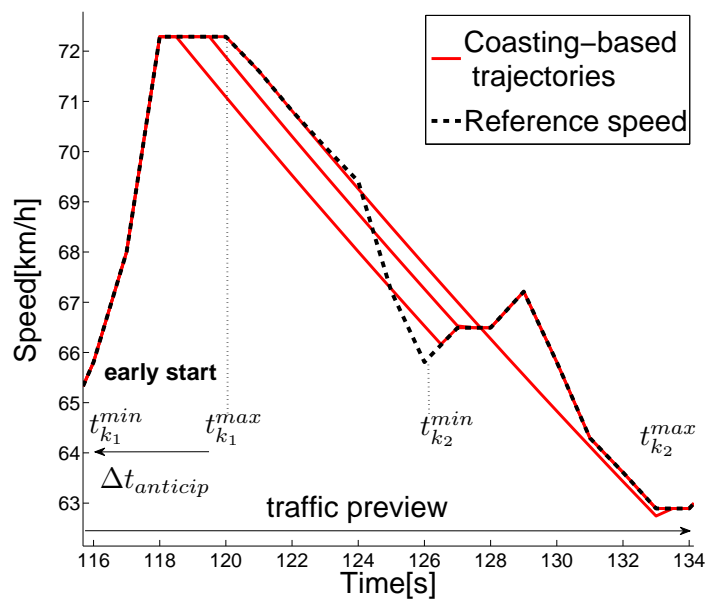

Fig. 14. Example of coasting trajectories for different starting points

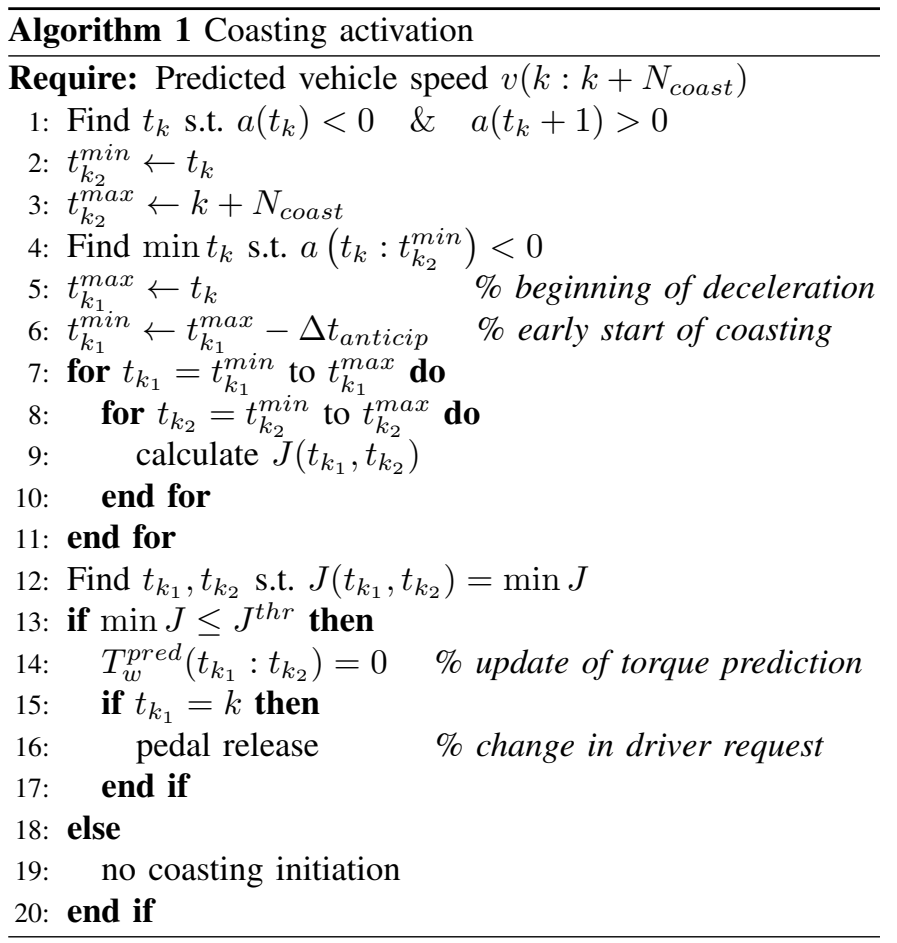

deviations). The following thresholds for the cost functions were empirically chosen:

$$
\begin{aligned}
J_{1}^{t h r} & =\left(\frac{5}{3.6}\right)^{2}+\alpha\left(\frac{1}{3.6}\right)^{2}+\beta\left(\frac{1}{T_{\text {coast }}^{\min }}\right)^{2} \\
J_{2}^{t h r} & =0.1+\alpha \frac{1}{3.6}+\beta \frac{1}{T_{\text {coast }}^{\min }}
\end{aligned}
$$

For $J_{1}$, this threshold value indicates that an average speed deviation of $5 \mathrm{~km} / \mathrm{h}$ is preferable (expressed in $\mathrm{m} / \mathrm{s}$ ), whereas for $J_{2}$ the term 0.1 is related to an average relative deviation. In both cases, a final speed error of $1 \mathrm{~km} / \mathrm{h}$ is desired.

If the cost function evaluation at each point is to be avoided, an approximation based on Gauss quadrature can be an alternative solution. This method is used to approximate the integral of a function, by using a decomposition in basic functions and 

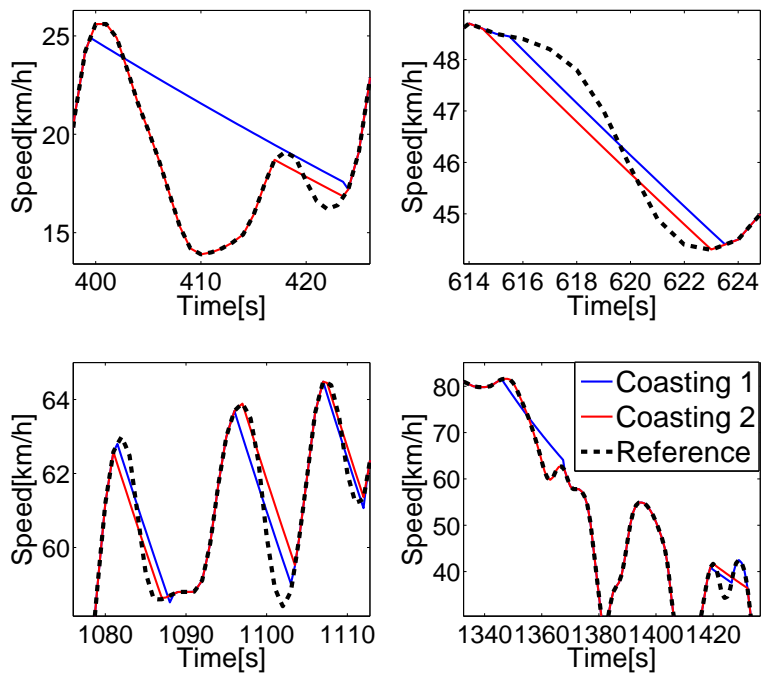

Fig. 15. Comparison between the speed profiles given by the 2 cost functions; speed profile - WLTC
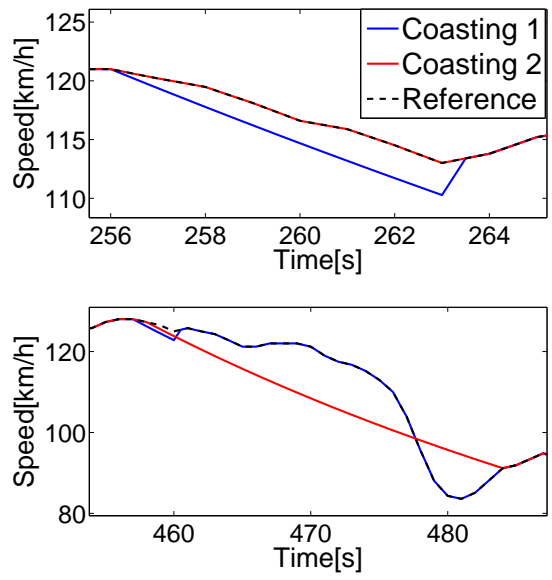

Fig. 16. Comparison between the speed profiles given by the 2 cost functions; speed profile - Artemis highway

evaluating them at some specific points between the domain of integration. It can provide good results if the initial function can be accurately approximated by a polynomial. Therefore, if a piecewise polynomial approximation for the reference speed can be found, then the aforementioned exhaustive search can be replaced with a faster evaluation at some points.

The standard drive cycles from Fig. 8 are not representative enough for this functionality, the activation of coasting does not make any visible improvement in the normalized consumption. The proposed strategy was only validated on basic case-studies, as presented in the previous subsection in Fig. 10 and 12. From Table III it can be concluded that coasting has the potential of reducing the consumption by $3-5 \%$, the gain depending on the driver behavior and the speed profile.

\section{CONCLUSIONS AND PROSPECTS}

In this paper, the predictive energy management problem of hybrid electric vehicles was addressed. Torque distribution and engine stop-start were jointly considered in an MPC framework. The advantages of MPC for this problem are the handling of constraints and simultaneous calculation of a block of commands, which allows the introduction of the engine stop decision, without the use of an additional, discrete optimization variable. The Model-in-the-Loop validation for different drive cycles shows that the MPC performance can be as close as $6 \%$ to the global optimum. The potential of free-wheeling in fuel consumption minimization was also analyzed. This strategy implies deviations from the reference speed profile, because the speed regulator is deactivated and the vehicle decelerates due to friction forces. Even in the context of the non violation of speed limits, the absence of obstacles and preservation of the total trip distance, the acceptance of the solution is subject to driver's behavior and remains an open topic. This functionality usually concerns constant speed sections on highway, but here the problem was extended to time-varying speed phases. Moreover, an analytical formulation was proposed through the evaluation of the time-wise speed deviation between the reference and the free wheeling speed. To avoid high compensations from the speed regulator, a penalty term was introduced to ensure that when a pedal is pressed, i.e. coasting deactivation, the vehicle speed is close to the setpoint. Future work may include improvements in the cost function to cope with constraints related to position, as well as a mechanism to handle changeof-mind situations.

\section{REFERENCES}

[1] L. Guzzella and A. Sciarretta, Vehicle Propulsion Systems, 2007.

[2] O. Grondin, L. Thibaut, P. Moulin, A. Chasse, and A. Sciarretta, "Energy management strategy for Diesel hybrid electric vehicle," IEEE Vehicle Power and Propulsion Conf., 2011.

[3] D. Opila, D. Aswani, R. McGee, J. Cook, and J. Grizzle, "Incorporating drivability metrics into optimal energy management strategies for hybrid vehicles," 47th IEEE Conf. on Decision and Control, 2008.

[4] S. Stockar, V. Marano, M. Canova, G. Rizzoni, and L. Guzzella, "Energy optimal control of plug-in hybrid electric vehicles for real-world driving cycles," IEEE Trans. on Vehicular Technology, vol. 60, 2011.

[5] S. di Cairano, D. Yanakiev, A. Bemporad, I. Kolmanovsky, and D. Hrovat, "Model predictive idle speed control: design, analysis and experimental evaluation," IEEE Trans. on Control Systems Technol., vol. 20(1): 84-97, 2012.

[6] T. Besselmann, P. Rostalski, and M. Morari, "Hybrid parameter-varying model predictive control for lateral vehicle stabilization," Proc. European Control Conf., 2007.

[7] M. Vajedi and N. Azad, "Ecological adaptive cruise controller for plugin hybrid electric vehicles using nonlinear model predictive control," IEEE Trans. on Intelligent Transportation Systems, vol. 17, 2016.

[8] P. Falcone, F. Borelli, H. E. Tseng, J. Asgari, and D. Hrovat, "A hierarchical model predictive control framework for autonomous ground vehicles," American Control Conf., 2008.

[9] N. Mueller, S. Strauss, S. Tumback, G. Goh, and A. Christ, "Next generation engine start/stop systems: free-wheeling," SAE Int. J. Engines, vol. 4(1): 874-887, 2011.

[10] H. Koch-Groeber and J. Wang, "Criteria for coasting on highways for passenger cars," SAE Technical Paper, vol. 2014-01-1157, 2014.

[11] L. Horrein, A. Bouscayrol, P. Delarue, J. Verhille, and C. Mayet, "Forward and backward simulations of a power propulsion system," IFAC Proc. Volumes, 8th Power Plant and Power System Control Symp., vol. 45, issue 21, pages 441-446, 2012. 
[12] G. Rizzoni, L. Guzzella, and B. Baumann, "Unified modeling of hybrid electric vehicle drivetrains," IEEE/ASME Trans. Mechatronics, vol. 4, No 2, 1999.

[13] K. Chen, A. Bouscayrol, A. Berthon, P. Delarue, D. Hissel, and R. Trigui, "Global modeling of different vehicles," IEEE Vehicular Technology Magazine, 2009.

[14] S. Ebbesen, P. Elbert, and L. Guzzella, "Battery state-of-health perceptive energy management for hybrid electric vehicles," IEEE Trans. Vehicular Technol., vol. 61, 2012.

[15] D. Zhao, R. Stobart, G. Dong, and E. Winward, "Real-time energy management for Diesel heavy duty hybrid electric vehicles," IEEE Trans. Control Systems Technol., vol. 23, 2015.

[16] T. Pham, J. Kessels, and P. van den Bosch ad R.G.M. Huisman, "Analytical solution to energy management guaranteeing battery life for hybrid trucks," IEEE Trans. Vehicular Technol., vol. DOI 10.1109/TVT.2015.2480745, 2015.

[17] L. Johannesson, S. Pettersson, and B. Egardt, "Predictive energy management of a 4qt series-parallel hybrid electric bus," Control Engineering Practice, vol. 17, pp. 1440-1453, 2009.

[18] C. Weng, X. Zhang, and J. Sun, "Adaptive model predictive control for hybrid electric vehicles power management," Proc. 32nd Chinese Control Conf., 2013.

[19] R. Dudek, V. Smidl, and Z. Peroutka, "Start - stop system for a city bus based on model predictive control," Industrial Electronics Society, IECON, 2014

[20] O. Sundstrom, L. Guzzella, and P. Soltic, "Optimal hybridization in two parallel hybrid electric vehicles using dynamic programming," Proc. of the 17th World Congress IFAC, 2008.

[21] L. Serrao, "A comparative analysis of energy management strategies for hybrid electric vehicles," Ph.D. dissertation, The Ohio State Univ., 2009.

[22] A. Sciaretta, M. Back, and L. Guzzella, "Optimal control of parallel hybrid electric vehicles," IEEE Trans. on Control Systems Technology, vol. 12, No. 3, 2004.

[23] C. Musardo, G. Rizzoni, Y. Guezennec, and B. Staccia, "A-ECMS: An adaptive algorithm for hybrid electric vehicle energy management," European Journal of Control, vol. 11:509 - 524, 2005.

[24] A. Sciarretta, L. Guzzella, and M. Back, "A real-time optimal control strategy for parallel hybrid vehicles with on-board estimation of the control parameters," Proc. IFAC Symp. Adv. Automotive Control, 2004.

[25] S. D. Cairano, W. Liang, I. Kolmanosky, M. Kuang, and A. Phillips, "Engine power smoothing energy management strategy for a series hybrid electric vehicle," American Control Conf., 2011.

[26] H. Borhan, A.Vahidi, A. Phillips, M. Kuang, I. Kolmanovsky, and S. D. Cairano, "MPC-based energy management of a power-split hybrid electric vehicle," IEEE Trans. on Control Systems Technol., vol. 20, No. 3, 2012.

[27] M. Bichi, G. Ripaccioli, S. Cairano, D. Bernardini, A. Bemporad, and I. Kolmanovsky, "A stochastic MPC approach for series hybrid electric vehicle power management," IEEE Conf. on Decision and Control, 2010.

[28] M. Josevski and D. Abel, "Energy management of a parallel hybrid electric vehicles based on stochastic model predictive control," 19th World Congress, IFAC, 2014.

[29] T. Kim, C. Manzie, and H. Watson, "Fuel economy benefits of lookahead capability in a mild hybrid configuration," Proc. of the 17th World Congress IFAC, 2008

[30] C. Manzie, T. Kim, and R. Sharma, "Optimal use of telemetry by parallel hybrid vehicles in urban driving," Elsevier, Transport. Research Part $C$ 25, 2012.

[31] R. Beck, A. Bollig, and D. Abel, "Comparison of two real-time predictive strategies for the optimal energy management of a hybrid electric vehicle," E-COSM - Rencontres Scientifiques de l'IFP, 2006.

[32] S. Hahn, H. Waschl, G. Steinmaurer, and L. del Re, "Extension of a linear optimal control strategy for HEV," European Control Conf., 2015.

[33] T. Nuesch, P. Elbert, M. Flankl, C. Onder, and L. Guzzella, "Convex optimization for the energy management of hybrid electric vehicles considering engine start and gearshift costs," Energies, vol. 7, 2014.

[34] N. Stroe, G. Colin, K. Ben-Cherif, S. Olaru, and Y. Chamaillard, "Towards a generic control-oriented model for HEV predictive energy management," 8th IFAC Int. Sym. Adv. Automotive Control, 2016.

[35] J. B. Rawlings, D. Angeli, and C. Bates, "Fundamentals of economic model predictive control," 51st IEEE Conf. on Decision and Control, 2012.

[36] N. Stroe, S. Olaru, G. Colin, K. Ben-Cherif, and Y. Chamaillard, "A twolayer predictive control for hybrid electric vehicles energy management," IFAC World Congres, vol. to appear, 2017.
[37] L. Serrao, S. Onori, and G. Rizzoni, "A comparative analysis of energy management strategies for hybrid electric vehicles," Journal of Dynamic Systems, Measurement and Control, vol. 133, 2011.

[38] V. Petrushov, "Coast down method in time-distance variables," $S A E$ Technical Paper 970408.

[39] M. Nagahara, D. E. Quevedo, and D. Nesic, "Maximum hands-off control: A paradigm of control effort minimization," IEEE Trans. on Automatic Control, vol. 61(3):735-747, 2016. 
Nicoleta Stroe received the Electrical Engineering Degree from University Politehnica Bucharest, Romania, in 2012 and the M. Sc. degree in automatic control from Supelec and University Paris-Sud, France, in 2013. She holds a Ph.D. degree in Energetics from University of Orleans, France from 2017 and currently she works at Renault, in the field of powertrain simulation. Her research interests include model-based control and optimization, with a focus on powertrain applications.

Sorin Olaru received the Electrical Engineering diploma and the MSc degree from University Politehnica Bucharest, Romania in 2001 and 2002 respectively. He holds a Ph.D. degree in automatic control from Supelec and the University Paris-Sud, France, from 2005. Currently he is a Professor in CentraleSupelec and member of the CNRS Laboratory of Signals and Systems, both within the Paris-Saclay University in France. He is involved in research projects related to embedded predictive control, fault tolerant control, and time-delay systems. His research interests include optimization-based control design, set-theoretic characterization of constrained dynamical systems and the numerical methods in control.

Guillaume Colin graduated an engineer school, the ESSTIN of the University of Nancy and obtain his master's degree in automatic control in 2003. He received his Ph.D. degree in Energetics at the University of Orleans, France in 2006 and its Habilitation to conduct research in 2013. He is currently Associate Professor with the University of Orleans. Since 2003, he has been with the PRISME Laboratory of the University of Orleans. He is also with the Ecole Polytechnique de l'Universite d'Orleans, where he is the Head of the Department of Technologies for Energy, Aerospace, and Engines. His research interests include powertrains and automatic control, particularly nonlinear control and optimization.

Karim Ben-Cherif graduated an engineer school, Polytechnic School of Algeria in 1999 and obtain his master's degree in automatic control in 2000 at University Orsay Paris XI. He received his Ph.D. degree in Applied Mathematics at the University Dauphine, France in 2004 and an Executive MBA in strategy in 2008. He is currently Powertrain Control team manager in Renault-Nissan Alliance.

Yann Chamaillard received the Ph.D. degree in automatic control from the University of Mulhouse, Mulhouse, France, in 1996. In 2008 he became a Full Professor with the University of Orleans, Orleans, France. He is the coordinator of Modeling, Optimization, and Control for the research group ECM of the PRISME Laboratory. His research interests include robust and predictive control, optimization, identification, modeling for control, engine control, and energy management for hybrid vehicles. Prof. Chamaillard has been a Vice Chair of the Technical Committee on automotive control of the International Federation of Automatic Control (TC 7.1) since 2008 and a Cochair of the Automatique et Automobile French Group of the GDR MACS since 2003. 